\title{
As Contradiçães do Nosso Desenvolvimento Econômico
}

\author{
Chagas Melo
}

$\mathrm{A}_{\mathrm{s}}$ contradições do nosso desenvolvimento econômico estão evidentes, demonstrando a necessidades de um nôvo planejamento desenvolvimentista.

Como salienta o relatório da Comissão Econômica das $\mathrm{Na}$ ções Unidas para África, versando sôbre os problemas relativos às técnicas de programação do desenvolvimento: "Le but général de tout programme de développement est de stimuler le "développement". Mais cela n'est pas suffisamment précis. Le terme "développement" peut se comprendre de bien des façons différentes. Dans un programme de développement, il est indispensable de préciser quelles sont les formes de développement envisagées. Parmi les buts - tous importants en Afrique - qu'un programme de développement peut viser, on peut citer les suivants: réduire la misère et la malnutrition des masses - passer d'une économie de subsistance à une économie monétaire - réaliser une plus grande diversification des exportations - isoler davantage l'économie des fluctuations des marchés mondiaux - encourager les exportations - accroitre la production aussi rapidement que possible - jeter les fondements du développement futur attirer des capitaux étranges - encourager les investissements nationaux - accroitre rapidement la consommation - freiner la consommation afin d'accroître les investissements - favoriser l'industrialisation - encourager l'agriculture, etc. On remarquera immédiatement que ces buts ne sont pas tous compatibles et qu'il peut être difficile de répartir entre eux des ressources limitées. II importe que le gouvernement indique exactement quelles sont ses intentions. Autrement, on ne comprendra bien ni les politiques qu'il adopte, ni les projets qu'il envisage".

Dentro dêsse pensamento, passaremos a examinar os efeitos: negativos da politica desenvolvimentista do qüinquiênio 1956-1960 em parte responsável por essas contradições.

A miséria e subnutrição continuam como constantes nas. regióes menos desenvolvidas do país.

O Nordeste com $32 \%$ da população do Brasil, contribui com menos de $14 \%$ da renda nacional, colocando-o entre as regiões mais subdesenvolvidas do mundo, abaixo do Paraguai e 
do Equador, e não muito acima dos niveis de renda da India e da Birmânia. (O Desenvolvimento Econômico do Nordeste do Brasil - Stefan Roboch-Etene - Fortaleza - Ceará - 1959).

A situação na Amazônia mostra, igualmente, que o desenvolvimentismo agravou as divergências regionais, solapando as bases politicas da nacionalidade.

Apesar dos bilhões de cruzeiros empregados na Amazônia por fôrça do artigo 199 da Constituição Federal, ou seja aquêle que manda aplicar 3\% das rendas tributárias da União no Plano de Desenvolvimento Econômico da Amazônia, a participação da região na renda nacional não se alterou como se vê no quadro abaixo.

AMAZÔNIA - PARTICIPAÇÃO NA RENDA NACIONAL

\begin{tabular}{|c|c|c|c|c|c|c|c|}
\hline \multirow{2}{*}{ ANOS } & REGIÃo & BRASIL & \multicolumn{5}{|c|}{$\%$ S/BRASIL } \\
\hline & \multicolumn{2}{|c|}{ (Cr\$ milhōes correntes) } & pArÁ & AMAZONAS & MARANH̃̃o & $\begin{array}{l}\text { MATO } \\
\text { GROSSO }\end{array}$ & REGL̃̃o \\
\hline $\begin{array}{l}1955 \ldots . \\
1956 \ldots \ldots \\
1957 \ldots \ldots \\
1958 \ldots \ldots\end{array}$ & $\begin{array}{l}23.742,0 \\
32.132,5 \\
32.942,3 \\
46.505,4\end{array}$ & $\begin{array}{r}579.072,0 \\
732.105,5 \\
871.896,0 \\
1.039 .539,8\end{array}$ & $\begin{array}{l}1,3 \\
1,3 \\
1,4 \\
1,3\end{array}$ & $\begin{array}{l}0,8 \\
1,0 \\
1,1 \\
1,0\end{array}$ & $\begin{array}{l}0,9 \\
0,9 \\
1,0 \\
1,1\end{array}$ & $\begin{array}{l}1,1 \\
1,1 \\
1,0 \\
1,1\end{array}$ & $\begin{array}{l}4,1 \\
4,5 \\
4,4 \\
4,4\end{array}$ \\
\hline
\end{tabular}

Fonte: SPVEA - "Política de Desenvolvimento da Amazônia - 1954/1960" - Volume I.

(Nota: os dados sôbre a renda nacional estão aquém da realidade, de acôrdo com os elementos formecidos e publicados pela Fundação Getúlio Vargas e que constam do nosso trabalho e que viriam reforçar a nossa tese pois a participação seria menos do que a constante do quadro acima).

A situação não foi diferente no Rio Grande do Sul onde a politica cambial seguida até 1961 descapitalizou a economia gaúcha como se lê do trecho abaixo transcrito, de autoria do Dr. José Augusto, sôbre a Crise da Economia Sul-Rio-Grandense - Revista Mensal da Confederação Nacional do Comércio Fevereiro de 1961:

"Assinalarei de início que a economia gaúcha até os fins da última década refletia uma situação de equilibrio consideràvel, colocando o Estado sulino entre os que melhor distribuída tinham a sua renda. Dava aos que ali residiam, ou aos que por lá passavam. a impressão de existir uma população vivendo feliz, certamente sem oferecer o aspecto de grandes fortunas individuais, mas também sem revelar o espetáculo de populações miseráveis e famintas, como ocorre por exemplo no Norte e no Nordeste, neste notadamente nos periodos da longas estiagens, das inclementes sêcas periódicas.

Naqueles tempos cabia um quinhão da renda pública a cada habitante da terra, na qual não havia gente sem trabalho. Todos 
encontravam meios de auferir o seu ganhão-pão, no cultivo dos campos ou no apascentar dos rebanhos. Nos fins da última década, ai por volta de 1948 e 1949 , e notadamente na década que neste ano de 1960 se encerra, a economia gaúcha passou a se debilitar e a crise cada vez mais se acentua, reclamando já agora medidas e providências que não devem ser proteladas.

Não há exagêro em afirmar que estamos ali diante de uma situação de clamor público. Os que lá forem, como comigo aconteceu ainda há poucos dias, bem podem avaliar. Clamam as chamadas classes conservadores ou produtoras, a agricultura, a indústria, o comércio, os sindicatos operários, o próprio govêrno do Estado, cada uma dessa categoria sentindo de perto os efeitos desastrosos da descapitalização em uma economia que perde o seu tradicional equilibrio. Os ecos dessa situação de clamor chegam até aqui ao Rio de Janeiro, capital que ainda é senão da vida politica do País, pelo menos das mais poderosas organizações econômicas e dos órgãos de ressonância pública que são os jornais ainda hoje aqui sediados, como os canalizadores naturais das aspirações e anseios e até das lamentações dos que sofrem em todo o Brasil".

A politica de transportes adotando como base o transporte rodoviário, embora nos tenha sido criada no qüinqüênio 1955 1960, foi intensificada nessa ocasião com a Lei $\mathrm{n}^{\circ} 2.975$, de 1956 , que altera a legislação sôbre combustivel liquido e lubrificantes, transformando o impôsto em "ad-valorem" aumentando, por conseguinte, a sua produtividade.

Das metas do qüinqüênio acima mencionado, uma das poucas. atingidas, apenas 9 das 30 - segundo o próprio Presidente Juscelino Kubitschek em palestra radiofônica no dia 22 de janeiro de 1961 - foi a de rodovias, com um total de $7.800 \mathrm{~km}$ construídos. Outros ramos de transportes foram esquecidos como o de ferrovias, marinha mercante, sòmente esquematizados no final do Govêrno e sem nenhuma realização de vulto, para os problemas de transportes no país.

O Brasil é, talvez, o único país do mundo, onde há predominância de $70 \%$ do transporte rodoviário, que é o mais caro, mesmo nos paises que têm condições para êle como Estados. Unidos (petróleo), Rússia (petróleo e condições geográficas), França e Alemanha (condições geográficas).

Sem petróleo suficiente para o consumo interno, com acidentes geográficos entre os centros populosos e industriais do. litoral e o interior, com grandes distâncias a percorrer, com pesadas cargas a transportar, ou sejam equipamentos, erigiram como. base do nosso sistema de transporte a rodovia, o menos indicado para o nosso caso, dada a nossa situação geográfica e econômica.

"Chega a ser ridículo o choque da política de petróleo com a politica de transportes no Brasil. Enquanto a primeira é nacio- 
nalista e luta pela auto-suficiência, a segunda é esbanjadora, tipo filhinho do papai rico. Quando a Lei 2.004 criou a Petrobrás, pondo fim à disputa bizantina em tôrno do entrega ou não entrega, a nação respirou aliviada. Parecia que o objetivo principal da constituição do monopólio estatal assegurava a meta sonhada da auto-suficiência de combustiveis. A conquista em pouco tempo do equilibrio final dos pratos da balança produção-consumo, que nos sugava (e suga) anualmente, transformando em fumaça milhões de dólares pagos graças ao café exportado.

O esfôrço ascensional da Petrobrás entusiasmou a todos, tapando a bôca até dos mais descrentes. Os números que medem o incremento da produção e do refino são elementos que todo brasileiro devia conhecer de cor, acompanhando suas flutuações com o mesmo interêsse com que seguem os altos e baixos do câmbio (infelizmente mais altos do que baixos), ou as variações do tempo.

A politica dos transportes é a antitese da primeira. A sua imagem invertida e destorcida em espelho côncavo. E' perigosa, contraproducente, pondo em risco todo o esfôrço para a libertação da importação de combustiveis.

$E^{\prime}$ fruto da incapacidade do Govêrno como órgão administrador dos transportes pesados nacionais, produzindo, devido sua incapacidade congênita, o descrédito nos sistemas que controla. Compreensível foi o seu amor à primeira vista pela indústria de automóveis. Ela conseguiu dar vazão ao complexo de fuga, libertando-o das frustaçóes recaldadas. O Rodoviarismo the permitia aparecer favoràvelmente perante a opinião pública desfazendo a impressão do seu fracasso nas Estradas de Ferro e Marinha Mercante". (Murilo N. Azevedo - Correio da Manhã: 19-1-62).

O financiamento do nosso desenvolvimento econômico através de emissões tem provocado grandes desequilibrios, refletindo-se no aumento exagerado do custo-de-vida, provocando uma maior espoliação do proletariado, e proletarizando a classe média que está desaparecendo no Brasil, asfixiada com uma tributação excessiva, como resultado da politica desenvolvimentista do Govêrno que, além do mais, esqueceu o homem, não the dando mais escolas e hospitais, diminuindo meios de subsistência e subtraindo da agricultura créditos que foram desviados para obras improdutivas.

Referindo-se aos "slogans" do chamado desenvolvimentismo diz o ilustre Deputado Barbosa Lima Sobrinho em discurso pronunciado na Câmara dos Deputados, no dia 9 de junho de 1961:

"O Brasil não pode parar - era o que uma publicidade bem orientada, e não pouco dispendiosa, repetia todos os dias. $\mathrm{E}$ para que não parasse, precisava de dinheiro. E como não havia 
dinheiro, fabricava-se sem parar o dinheiro, fabricava-se papel moeda, para que o Brasil não parasse nunca, empurrado pelas máquinas de imprimir notas de todos os valores. Alguém (dizia a propaganda industriosa) precisava pagar o desenvolvimento do país. Se o estrangeiro não nos dava recursos para isso, era o caso de fazer o povo concorrer para êsse objetivo, não através de contribuições que êle não podia dar, mas de sacrifícios, que ihe eram impostos pelo aumento do custo-de-vida, escudeiro fiel do inflacionismo desatinado. Vinha, então, o outro "slogan" tocado de uns tons de exaltação nacionalista: o povo brasileiro paga o desenvolvimento que o estrangeiro não quer promover. Mas como pagava o povo êsse desenvolvimento? Através da inflaçäo e do aumento do custo-de-vida. E através do custo-de-vida, o que se verificava era que só o povo pagava o desenvolvimento do país, enquanto os empreiteiros de tôda ordem, uma grande burguesia próspera, acumulava fortunas imensas e ainda encontrava saldos para as caixas e as campanhas politicas do futuro. O "slogan" era apenas um engôdo ou, pior do que isso, um escárnio, com que se ilaqueava a boa-fé de um povo simples e confiante e que não podia estar muito a par da relação existente entre os jorros de papel-moeda de um inflacionismo ilimitado e a alta de preços dos gêneros de primeira necessidade, com que alimentava suas famílias. O que vale dizer que o "slogan" se esquecia de acentuar que só o povo pagava o desenvolvimento do Brasil. Pagava o desenvolvimento quem menos o poderia pagar, quem menos deveria fazê-lo. Prova de que a vaidade dos governantes, mesmo quando revestida do sorriso simpático dos bons moços e das atitudes harmoniosas das vedetas, não hesitava em adotar uma orientação, que se confundia com a crueldade, quando aumentava, sem escrúpulos, a sobrecarga de um povo pobre, assim imolado à fortuna e à prosperidade da nova classe desenvolvimentista".

A política do Govêrno brasileiro no qüinqüênio 1955-1960. desorganizou a agricultura, principalmente a de subsistência que é a que nos dá o feijão, arroz, batata, milho e outros gêneros alimentícios em benefício da agricultura de exportação - café por exemplo, para comprá-lo e estocá-lo, pois exportamos apenas $40 \%$ da produção, despendendo bilhões de cruzeiros, imobilizando nos armazéns o café comprado com o dinheiro da inflação.

A politica desenvolvimentista no cômputo geral, não apresentou resultados positivos, à exceção de alguns setores industriais, como se pode ver das estatisticas publicadas pela Fundação Getúlio Vargas.

O incremento do produto real que chegou a $6,3 \%$ em 1948 , $6,1 \%$ em 1951 e 1952 e $7,9 \%$ em 1954, atingiu de 1955 a 1959 uma média de 3,5\% para apenas melhorar em 1960 que foi de $4,2 \%$. Em 1961, quando nos sete primeiros meses o govêrno 
abandonou a politica desenvolvimentista com um hiato deflacionário para conter os desequilibrios, o produto real subiu de $7,2 \%$, uma das taxas mais elevadas dos últimos oito anos.

Com a politica de crédito e de preços mínimos de apenas 7 meses do Govêrno Jânio Quadros, tivemos uma significativa expansão do setor agrícola que cresceu $10,2 \%$, o triplo da média do período 1956-960, que foi apenas de 2,6\%.

Ao iniciar em 1946, o programa desenvolvimentista das "Metas", deveria o Govêrno ter pensado antes em um plano financeiro para custeá-los, e não emitir para desenvolver, principalmente em obras improdutivas.

A tendência depressiva das exportações já era evidente em 1956. Basta lembrar, como salientou o Ministro Lucas Lopes em 1959, no periodo de 1948-56, o volume da exportação mundial aumentou de 77\%; as exportações da Europa Ocidental triplicaram, as da América do Norte aumentaram de $40 \%$ e as da área do esterlino de $53 \%$. Mesmo na América Latina, em seu conjunto, o "quantum" das exportações cresceu de $21 \%$, e alguns países de rápido desenvolvimento econômico como o México, lograram pràticamente dobrar o volume exportado. Pois bem, nesse periodo de intensa expansão do comércio mundial, o volume físico das exportações brasileiras declinou em cêrca de $15 \%$. Isso é tanto paradoxal quanto, no mesmo período, a nossa demanda de importações, decorrente do processo do desenvolvimento econômico, aumentava vertiginosamente. Assim, ao passo que o indice do volume físico das exportações declinava de 100 para 85, em 1957, o das importações subia de 100 para 156.

Uma politica ativa de exportações que deveria ter sido seguida como base de qualquer politica de desenvolvimento, não foi levada em consideração pelos administradores.

As exportações que eram de 1 bilhão e quatrocentos milhões de dólares em 1955, cairam em 1959 para 1 bilhão e duzentos e oitenta e dois milhões de dólares, reduzindo a nossa já diminuta capacidade de importar.

O financiamento das importações necessárias às obras do desenvolvimentismo foi conseguido através de empréstimos nos Es tados Unidos. O do custo interno à custa de maciças emissões de papel-moeda.

Os resultados dessa imprevidência foram dois: a inflação galopante no «front» interno e dividas acumuladas no exterior.

Comentando o nosso endividamento no exterior disse o Embaixador Roberto Campos, em entrevista ao Correio da Manhã de 29 de setembro de 1961, o seguinte: "que nos princípios do ano em curso a situação cambial do pais era das mais criticas, pois havia compromissos de grande monta venciveis a prazo curto, decorrentes da acumulação das promessas de venda de câmbio, 
contratos cambiais, vencimento de prestações relativas a fornecimentos especificos (a curto e médio prazos), além da dívida consolidada, a longo prazo, que embora sem maior expressão numérica, caracterizava-se pela concentração temporal dos vencimentos. As dividas brasileiras para com os principais credores da sua área de negociações - Alemanha, França e Itália - tinham $41 \%$ de seus vencimentos programados para o qüinqüênio que se iniciava. Salientou que a taxa máxima do pagamento dos países subdesenvolvidos deve situar-se entre 8 e 12 por cento de suas exportações anuais. Para o exercício de 61 o programa de pagamentos de crédito orçava em 760 milhões de dólares, ou seja, a quase totalidade da receita cambial proveniente das exportações".

As medidas adotadas pelo Govêrno em 1961, incremento do comércio exterior já deram os primeiros resultados com o aumento das nossas exportações.

Qualquer politica de desenvolvimento econômico deve tomar por base o lema exportação intensiva para o desenvolvimento, evitando que se aumente o caos social e econômico em que vive o Brasil, que tem todos os elementos materiais para se desenvolver dentro da ordem, da paz e dos princípios democráticos e cristãos de vida. 